Article

\title{
Comparing Two Methods of Determining Infiltration Rates of Permeable Interlocking Concrete Pavers
}

\author{
Peter W.B.Nichols ${ }^{1, *}$, Terry Lucke ${ }^{1}$ and Carsten Dierkes ${ }^{2}$
}

1 Stormwater Research Group, School of Science and Engineering, University of the Sunshine Coast, Maroochydore DC 4558, Australia; E-Mail: tlucke@usc.edu.au

2 Urban Water Management, Frankfurt University of Applied Sciences, Frankfurt am Main 60318, Germany; E-Mail: Carsten.Dierkes@fb1.fh-frankfurt.de

* Author to whom correspondence should be addressed; E-Mail: pnichols@usc.edu.au;

Tel.: +61-4-5456-5787; Fax: +61-4-5430-2881.

Received: 30 May 2014; in revised form: 30 July 2014 / Accepted: 4 August 2014 /

Published: 8 August 2014

\begin{abstract}
Adequate infiltration through Permeable Interlocking Concrete Pavements (PICPs) is critical to their hydraulic performance. Detected by monitoring infiltration performance, reduced infiltration rates can indicate that maintenance is required. Measurement of infiltration rates has previously been problematic on PICPs because of a lack of accepted standard methodologies and the practical difficulties in modifying existing testing methodologies. On large sites, standard methodologies necessitate multiple measurements to achieve accuracy. Standard methods also contend with practical issues such as sealing the rings to the surface to prevent lateral water flow. This study examined the performance of two PICP surface infiltration rate measurement methods: a modified double-ring infiltrometer (DRIT), and a specially designed rainfall simulation infiltrometer (RSIT). A positive correlation $\left(R^{2}=0.85\right)$ of results was found between the two, demonstrating that the RSIT was comparable to the DRIT. The modified DRIT produced surface infiltration results approximately $60 \%$ higher than the RSIT results. The RSIT provided lower variation between tests, requiring fewer measurements in large sites whilst still maintaining accuracy, thereby improving testing efficiency. The new RSIT method also eliminates some of the practical difficulties with existing methodologies such as unrealistic pressure heads artificially increasing infiltration rates, and the use of sealant under test measurement infiltration rings.
\end{abstract}


Keywords: Permeable Interlocking Concrete Pavements; clogging; infiltration testing; water sensitive urban design

\section{Introduction}

It is widely accepted that urbanisation results in an increase in the area of land covered by impervious surfaces including roads, driveways and car parking areas [1-3]. This results in an increase in stormwater runoff which may lead to pollution in the form of soil erosion (suspended solids) and other contaminants such as nitrogen, phosphorus, and heavy metals being transported uncontrolled through the environment [4]. Implicitly, impervious surfaces reduce infiltration into the soil and decrease groundwater recharge, while increasing stormwater runoff volumes and flow rates, potentially causing downstream flooding. Increased stormwater runoff volumes can cause significant reductions in downstream water quality [5].

In recent years, the treatment of stormwater in urban areas has become a priority issue for those responsible for planning, construction, and maintenance of new and existing developments. The relatively recent initiative of Water Sensitive Urban Design (WSUD) in Australia has highlighted the need for adequate treatment of stormwater runoff from urban developments. WSUD is a similar design philosophy to Low Impact Development (LID) in the US, and Sustainable Urban Drainage Systems (SUDS) in Europe. WSUD is the integration of urban planning with the management, protection and conservation of the urban water cycle that ensures urban water management is sensitive to natural hydrological and ecological processes. The guiding principles of WSUD are centred on achieving integrated water cycle management for the development of urban areas. The Commonwealth Scientific and Industrial Research Organisation (CSIRO) [6] reported these principles as being:

(a) reducing potable water demand through water efficient appliance, rainwater, and grey-water reuse;

(b) minimising wastewater generation and treatment of wastewater to a standard suitable for effluent reuse opportunities and/or release to receiving waters;

(c) treating urban stormwater to meet water quality objectives for reuse and/or discharge to surface waters; and

(d) using stormwater in the urban landscape to maximise the visual and recreational amenity of developments.

\subsection{Permeable Pavements}

The use of permeable pavements in place of traditional impervious surfaces meets many of the WSUD principles. Permeable pavement systems have been used globally for over two decades as a WSUD control measure to reduce both peak stormwater flows and pollution loads [7-10]. Permeable pavements have been shown to significantly reduce stormwater runoff volumes and increase evaporation compared to conventionally constructed pavements. They also improve water quality via the filtration processes that can occur within the pavement structure [7-10]. Primary stormwater treatment takes place through the removal of suspended solids during infiltration of the stormwater into the pavement structure. The suspended solids are captured in the voids within and between individual paving joints, 
and in some cases, within the pavement material itself [9]. There have been numerous research studies outlining the dual benefits of permeable pavements in terms of supporting pedestrian and vehicular traffic loads and the control and treatment of stormwater [7,10-12].

There are two main types of permeable pavements: monolithic and modular. Monolithic types include permeable concrete and permeable asphalt which are designed to promote stormwater infiltration through the pavement surface. The majority of modular permeable pavement systems consist of concrete blocks or pavers with open joints which allow infiltration between the pavers. These are generally called Permeable Interlocking Concrete Pavers (PICPs). The stormwater infiltrates through the PICP surface and bedding layers and then either permeates into the surrounding soil and into the groundwater table, or it is discharged into the underground stormwater drainage system through subsurface drainage pipes incorporated into the pavement structure (Figure 1).

Figure 1. Typical Permeable Interlocking Concrete Pavement (PICP) structure.

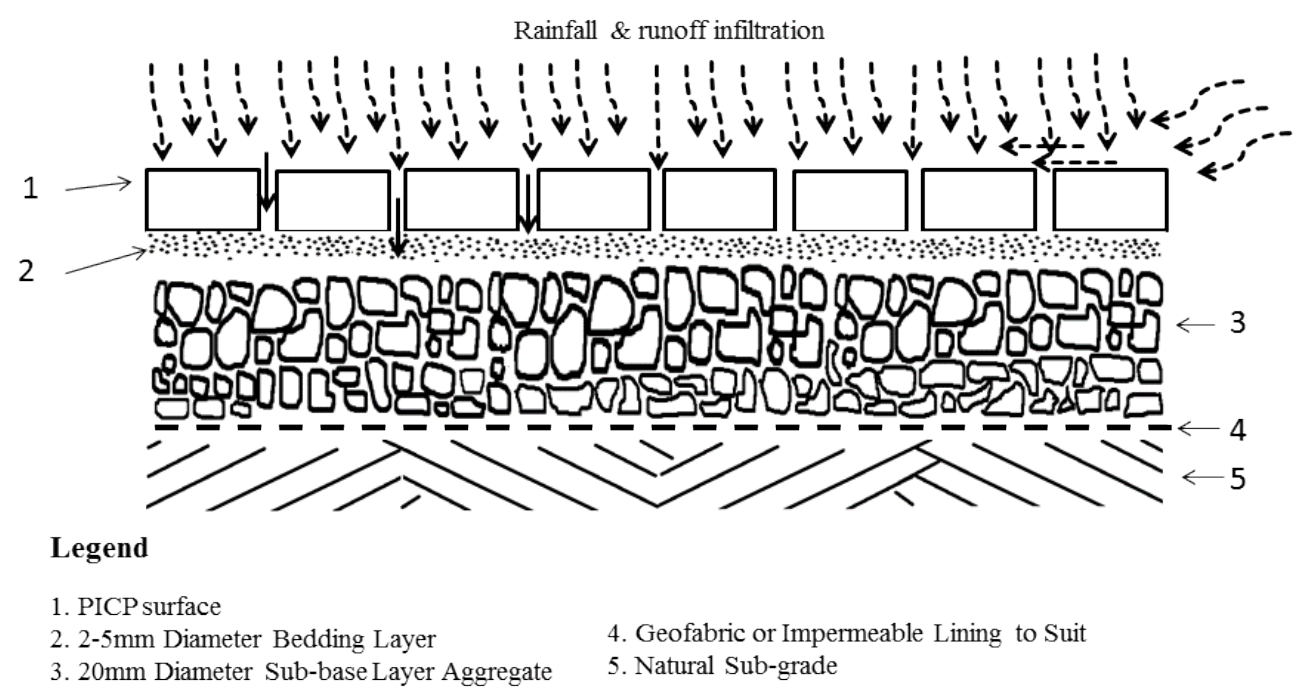

PICPs improve water quality by trapping sediment from stormwater runoff thereby reducing downstream pollution loads. The trapping of these fine sediments is a critical function of PICPs. This process of sediment capture has also been shown to significantly reduce the performance of PICPs over time due to clogging. Although infiltration rates of newly installed pavements have been shown to be high [12-14] these rates are known to diminish over time $(0-19,000 \mathrm{~mm} / \mathrm{h})$ due to clogging, potentially leading to a reduction in useful lifespan, increased maintenance and replacement costs [15]. Previous research has demonstrated that clogging takes place in the spaces within and between the pavement and bedding layers and this causes a reduction in the pavement infiltration capacity after a few years in service $[7,12,16,17]$. Other potential reasons for lower PICP infiltration rates over time include poor installation and construction practices, lack of adequate maintenance, and unfavourable environmental conditions such as loose soils or excessive tree litter at the pavement location [18-21].

Clogging can be controlled by regular maintenance such as vacuum sweeping or pressure washing that effectively remove or breakup clogging material [7,11]. Although some maintenance requirements have been specified, because PICPs are still a relatively new technology, maintenance has yet to be categorically defined across the full range of installation types and conditions. The lack of information 
regarding maintenance requirements for PICP systems has been highlighted as potentially limiting their broader acceptance and use [18,20].

One way to evaluate the performance of PICPs in order to determine maintenance requirements is to monitor changes in the PICP infiltration rate over time. Reduced infiltration rates can indicate that maintenance is required. Measuring infiltration rates has previously been problematic for a variety of reasons, including: a lack of an accepted standard methodology applicable for use on permeable pavements; the practical difficulties in modifying and applying existing testing methodologies, and the difficulty in developing a single methodology that could be used across the full range of permeable pavement types [14,22].

This study compares the results of a new permeable pavement surface infiltration testing methodology developed at the University of the Sunshine Coast (USC) based on rainfall simulation, with results obtained using the previously established modified ASTM D3385-09 double-ring infiltration testing method.

\subsection{Previous Surface Infiltration Testing}

The standard field test generally used to measure infiltration through soils uses a double-ring infiltrometer (ASTM D3385-09) [23]. The Double-Ring Infiltrometer Test (DRIT) methodology involves driving two rings (a $600 \mathrm{~mm}$ diameter outer ring, and a $300 \mathrm{~mm}$ inner ring) a certain depth into the soil (usually $150 \mathrm{~mm}$ deep for the outer ring and between 50 and $75 \mathrm{~mm}$ deep for the inner ring). Two rings are used to prevent or minimise lateral movement of water during the test. Water is then added to the rings at an appropriate flow rate in order to maintain a constant head in both rings over the duration of the test. The volume of water added over time is then used to calculate the infiltration rate of the soil.

Undertaking the DRIT on hard pavements requires two modifications to the standard methodology. First, because of the high infiltration rates of permeable pavements, a large volume of water can often be required to undertake the tests according to the ASTM D3385-09 method. To overcome this issue, a variation of the DRIT using a falling head method has also been performed in the past [18]. In the falling head variation, the rings are filled with water and the time taken for the water level in the central ring to fall a certain distance is recorded. The change in water level over time is then used to calculate the infiltration rate. To enable effective application of the DRIT, this study used the falling head variation of the method to measure the PICP surface infiltration rate.

The second modification is required because it is not possible to penetrate the double rings through the solid surface of PICPs. Previous permeable pavement infiltration studies using the ASTM D3385-09 have modified the methodology and used some type of putty, silicone or flexible material to temporarily seal the edges of the rings onto the pavement surface to conduct the tests $[7,17,18,22,24,25]$. However, the results obtained using these modified methods have been shown to be highly variable and inconsistent [20,22].

A limitation to the accuracy of ring infiltrometers on hard surfaces is the head of pressure (water level) generated during tests [26]. Use of both the constant-head and falling-head methods involves the use of unrealistic water depths that force the water through the surface under pressure due to the weight of the water above. Constant-head pressure tests are known to produce abnormally high infiltrations rates 
and the falling-head method is known to produce infiltration rates that vary over time depending on the water level above. Dougherty [27] affirmed that infiltration tests using near-zero head conditions are more representative of natural rainfall or sheet flow runoff events.

Another problem with the current test methodology is the amount of time required to undertake multiple tests over large areas of pavement to determine average infiltration rates. Bean [18] resolved this issue by an initial visual assessment to find a representative area of the PICP prior to testing thereby reducing the number of tests required.

The limitations of the existing DRIT are significant barriers to obtaining accurate, practical, and realistic infiltration rates of PICPs. A more accurate and less time consuming method to measure the infiltration rates of PICPs is needed [22] to assist asset managers to determine maintenance requirements.

\subsection{Rainfall Simulator Infiltrometer Test}

In order to replicate natural rainfall conditions in infiltration measurements on PICPs, a number of previous studies have incorporated rainfall simulation techniques into their testing methods $[7,16]$. These studies established that the equipment used was successful at simulating rainfall events. However, they also found the tests were expensive, complex, relied on a large amount of test equipment and were difficult to move from site to site.

Although not specifically designed to determine infiltration rates, Herngren [28] designed a rainfall simulator for application to urban stormwater quality research. His rainfall simulator was designed to replicate both the physical and chemical characteristics of rainfall in order to study the build-up and wash-off of pollutants from pavement surfaces. He found that rainfall simulation can eliminate the constraints of variability in intensity and occurrence, and the non-uniformity of natural rainfall when undertaking rigorous scientific research into urban stormwater quality. Meyer [29] found rainfall simulator design and function to be highly dependent on the needs of the particular research and recommended any new system be suited to the particular purpose for which it was being built. An industry-accepted infiltration testing methodology that incorporates realistic rainfall simulation techniques into the measurement processes has yet to be developed.

With the above studies in mind, this research had a particular focus on the design and testing of a new methodology for a more accurate and simple measurement of the infiltration rate of water through permeable pavements.

The main objectives of this study were to develop an accurate PICP infiltration measurement methodology to:

- $\quad$ achieve results comparable to accepted methodologies;

- $\quad$ achieve more realistic infiltration conditions through the use of a rainfall simulator;

- resolve a number of limitations of accepted methodologies such as:

- $\quad$ unrealistic water pressures (falling-head and constant-head);

- $\quad$ lateral water leakage (the need for a sealant);

- $\quad$ portability of the system (making field testing in a variety of locations simple and easy) and,

- $\quad$ reduce the need for multiple tests on large sites (increasing testing efficiency). 
In order to provide objective comparisons between the two methodologies, time required to set up and complete the tests, ease of use of the equipment, and volumes of water used during the test was also recorded. The average setup time for each RSIT was found to be $1 \mathrm{~min}$. Individual tests were completed in an average of $2 \mathrm{~min}$. Average water volumes used per test were found to be $60 \mathrm{~L}$. In contrast, the DRIT setup time was 20 min per test. Ease of use for each test was rated easy, average, or difficult (1-3). The average ease of use ranking for the RSIT was found to be "easy". Results from these comparisons may aid with future testing of PICPs and assist in identifying future maintenance requirements.

\section{Methodology}

This study compared the results obtained from a series of tests using two methods for measuring infiltration rates of PICPs. The modified DRIT was compared with the newly developed rainfall simulation infiltrometer RSIT test.

A purpose-built PICP test facility at USC was constructed to specifically undertake studies on PICP performance. The PICP test sites were subjected to replicate testing over a 12 month period using both test methodologies. A minimum of three replicate tests were completed at each of the sites. Results were analysed and compared to determine the accuracy of each method.

\subsection{USC PICP Test Facility}

In 2010, a specially designed $120 \mathrm{~m}^{2}$ permeable pavement testing facility was installed in one of the car parking areas at USC (Figure 2). The test facility is utilised as the taxi waiting area, drop-off and pick-up point for the University. The testing undertaken in this study was conducted on the surface of the PICP testing facility.

Figure 2. Test locations: (a) after construction; and (b) during construction, showing the six separate treatment sites.

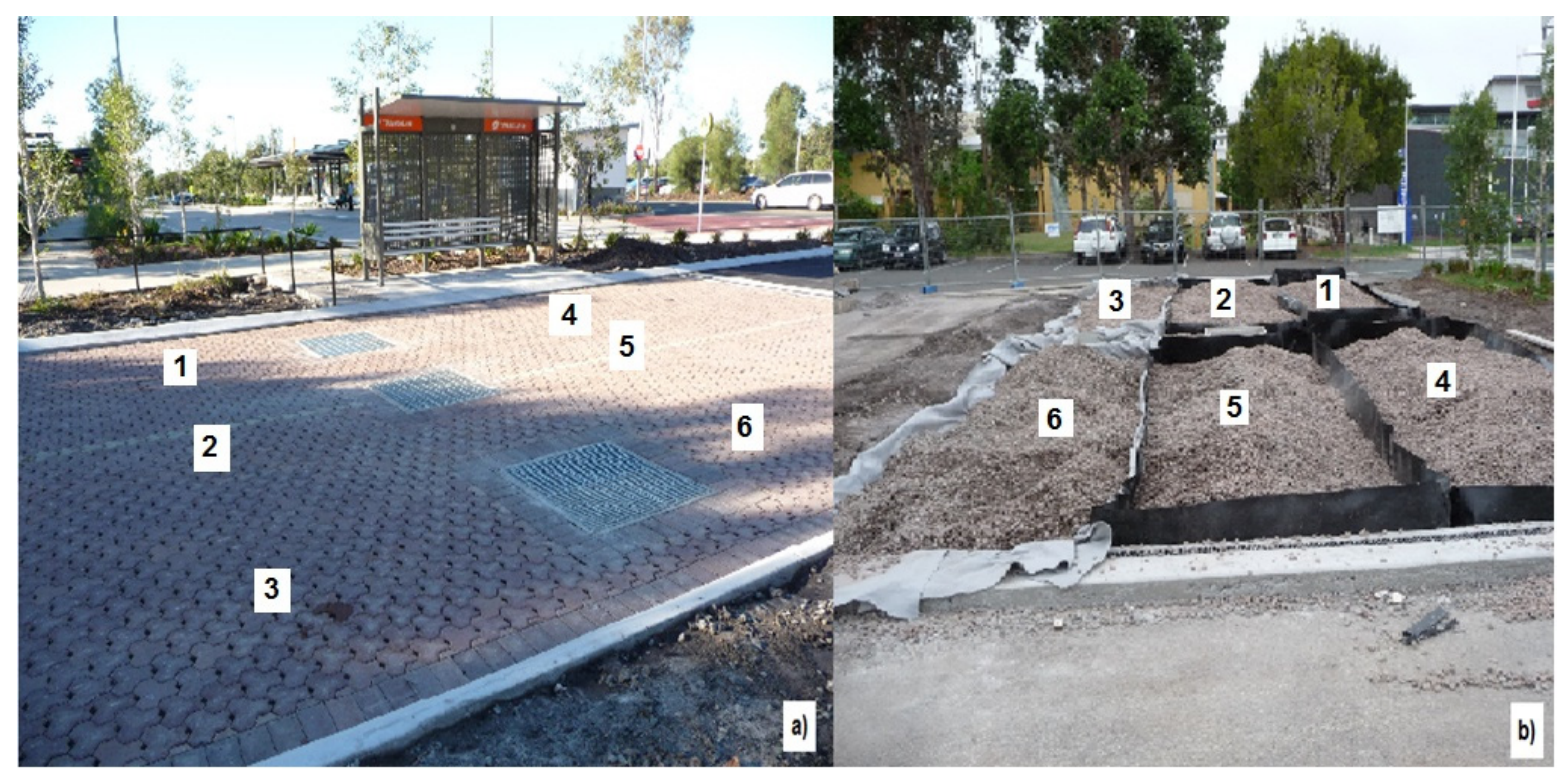


The test pavement is comprised of six sites incorporating three different construction techniques (Figure 2, Table 1). Comparative analysis of the impact of different construction techniques on infiltration rates was completed including: depth of aggregate layer, geofabric layer, and impermeable liner. Another factor hypothesized to potentially affect infiltration rate differences between sites included clogging caused by organics from adjacent garden beds (Sites 1, 3, 4 and 6). Organics included material deposited from pine bark $(20 \mathrm{~mm}$ diameter) mulched garden beds and She-oak (Casuarina cunninghamiana) leaves ( $2 \mathrm{~mm}$ diameter, $60 \mathrm{~mm}$ long) from adjacent overhanging trees. Two factors that were hypothesized to have little impact on infiltration rates over time were the depth of the subbase aggregate layer and the inclusion of an impermeable liner during construction.

Table 1. Range of different construction techniques used across sites.

\begin{tabular}{ccccc}
\hline Site & Geofabric layer & Geofabric liner & Aggregate depth & Impermeable liner \\
\hline 1 & No & No & $300 \mathrm{~mm}$ & Yes \\
2 & No & No & $480 \mathrm{~mm}$ & Yes \\
3 & Yes & Yes & $480 \mathrm{~mm}$ & No \\
4 & No & No & $300 \mathrm{~mm}$ & Yes \\
5 & No & No & $480 \mathrm{~mm}$ & Yes \\
6 & Yes & Yes & $480 \mathrm{~mm}$ & No \\
\hline
\end{tabular}

\subsection{DRIT Infiltration Testing}

The DRIT modified for hard pavement testing was performed three times on separate days following a three day intermittent period (Figure 3). Ensuring a watertight seal for the duration of the test was at times difficult, as was removing the sealant from the pavement surface after the test has been completed. A substantial volume of water was required to maintain the necessary water levels. A portable high pressure pump, generator, and $2000 \mathrm{~L}$ water tank were therefore used to supply the flow rate required for the testing.

Figure 3. Double ring infiltration test on PICP.

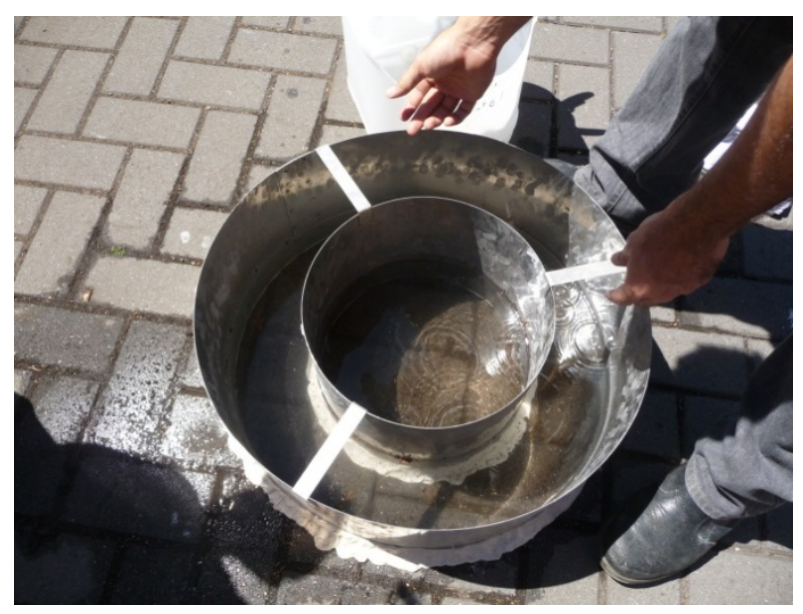

The pavement was pre-saturated in accordance with ASTM D3385-09. Water was then supplied to the inner and outer rings to an initial depth of $40 \mathrm{~mm}$. Care was taken to ensure the levels in both rings were the same during testing. Water depth measurements were taken at $5 \mathrm{~s}$ time intervals until the 
infiltration of the $40 \mathrm{~mm}$ water was complete. This process was repeated until the measured infiltration rate was within $\pm 10 \%$ for each test.

\subsection{RSIT Infiltration Testing}

The RSIT test rig consisted of a square steel frame fixed with a series of PVC pipes on top (Figure 4a). The RSIT included an inner and outer "ring" that were separated by $3 \mathrm{~mm}$ thick Perspex ${ }^{\circledR}$ sheeting. The area of the inner ring was $0.50 \mathrm{~m}^{2}$. The outer ring was included to reduce lateral flow effects. Inner and outer rings of PVC pipe were designed to replicate the water supply of a dual ring system used in the standard DRIT methodology. Rainfall simulation was achieved by supplying water to the RSIT through a series holes $(2.5 \mathrm{~mm}$ diameter $)$ drilled into the underside of the pipes $50 \mathrm{~mm}$ apart. Water was supplied to the RSIT device using a pump and a water tank mounted on a trailer. The flow of water was controlled via flow meters and valves. In order to visually simulate rainfall droplets, the jets of water flowing from the holes in the PVC pipe were passed through two horizontal wire gauze sheets to break the flow into droplets (Figure $4 \mathrm{~b}$ ) prior to contacting the pavement surface.

Figure 4. (a) Rainfall simulator; (b) Rainfall simulator in action.

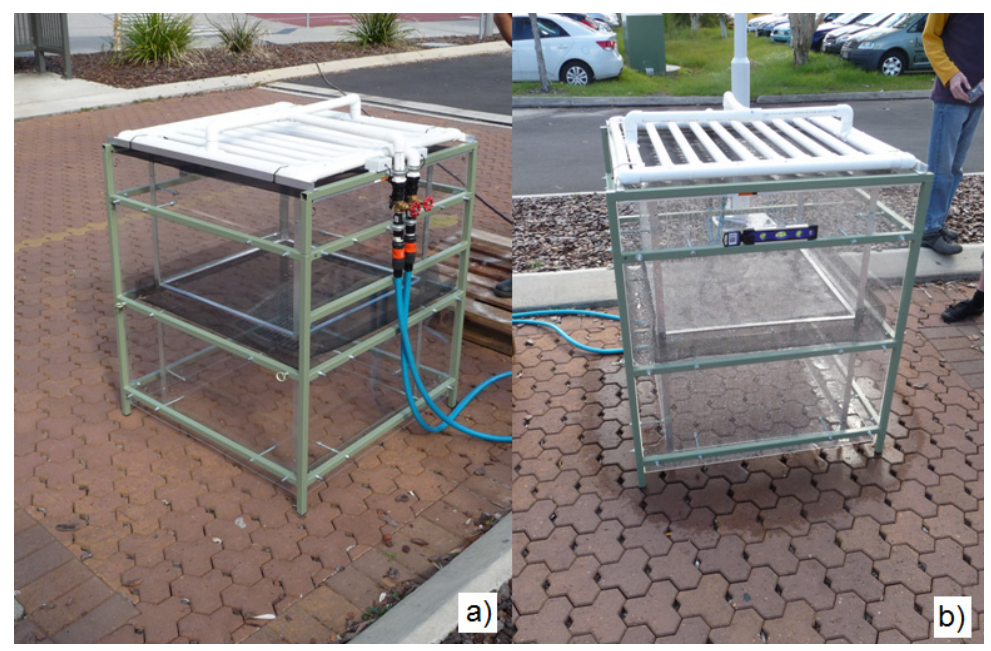

During the RSIT the maximum infiltration capacity of the pavement was identified as when water started visibly ponding on the pavement surface outside the framed area. Once ponding was observed, flow meter readings were recorded and this was classified as the maximum infiltration capacity of the site (Figure 5).

Replicate testing of the pavement using both the DRIT and RSIT methods provided scope for appropriate statistical analysis and interpretation of any potential spatial and temporal variation. The potential variation in measurements between different field operators is also considered an important variable in the accuracy of any infiltrometer [22]. To overcome this potential source of error all measurements were undertaken by at least two operators in this study. The average of these measurements was used in the analysis of the results.

Regression analysis was used to determine whether there was any relationship between the two testing methods. A scatter plot and linear trend line was also completed to check the strength and the 
direction of the trend, and the coefficient of determination $\left(R^{2}\right)$ was used to determine the regression model fit.

Figure 5. Water ponding on pavement surface under rainfall simulator.

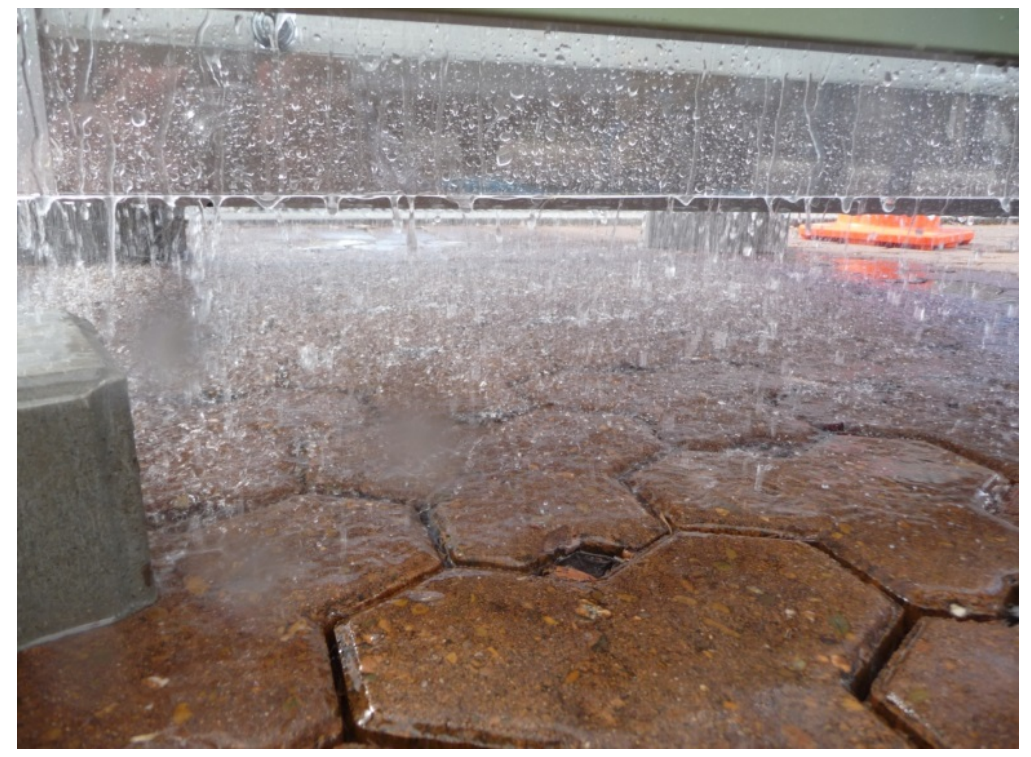

\section{Results}

At all of the sites tested, infiltration rates observed using the DRIT method were substantially higher than those measured using the RSIT. Average infiltration rates of over $9600 \mathrm{~mm} / \mathrm{h}$ were recorded using the DRIT compared to an average of $3600 \mathrm{~mm} / \mathrm{h}$ using the RSIT. Variation between the two methods was large. On average the DRIT method produced $60 \%$ higher measured infiltration rates when compared to the RSIT method. Higher initial infiltration rates were associated with greater disparity between the two methods (Figure 6). This suggests that the RSIT has a lower degree of variability between tests when compared to the DRIT, providing more consistent results from site to site.

Figure 6. Comparison of average PICP infiltration rates obtained using the double-ring infiltrometer (DRIT) and rainfall simulation infiltrometer (RSIT) methods.

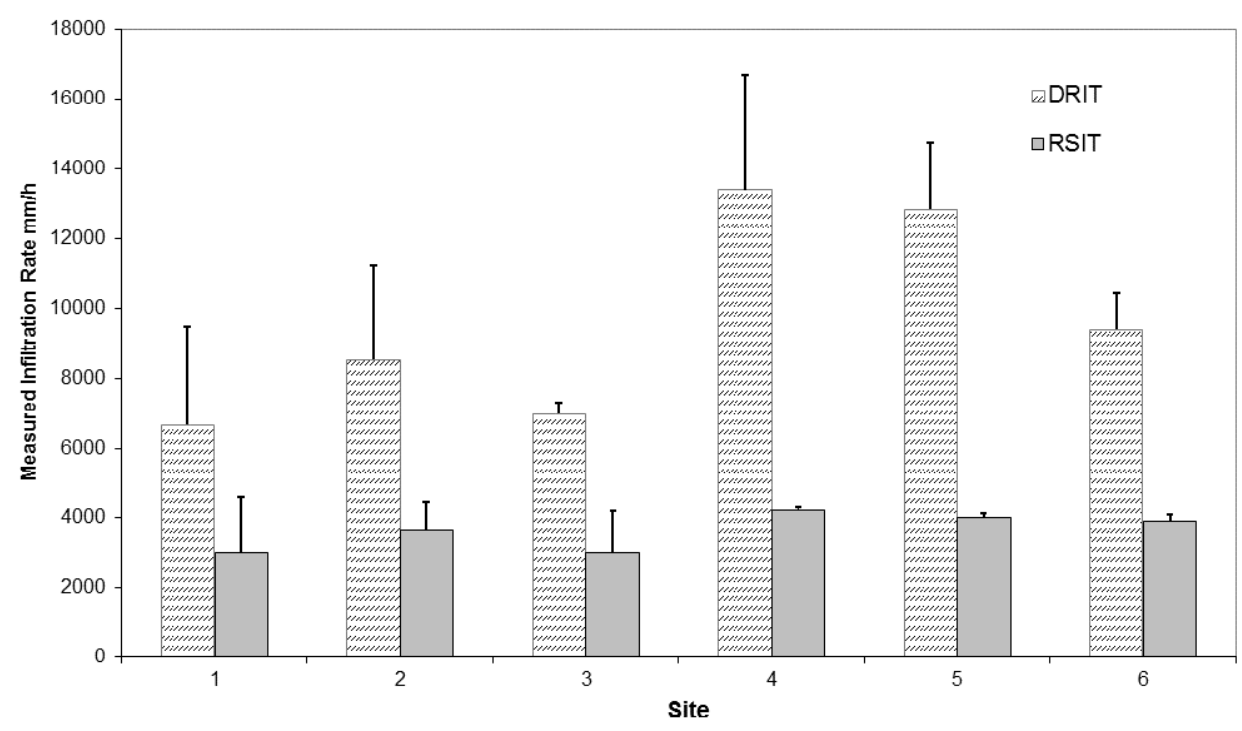


A linear regression analysis $(n=6)$ was undertaken and a strong correlation of results was found between the two methods. The coefficient of determination $\left(R^{2}\right)$ was found to be 0.8512 , meaning that over $85 \%$ of the total variation may be explained by a strong linear relationship between the two variables (Figure 7).

Figure 7. Regression analysis between DRIT and RSIT methods showing strong correlation of results.

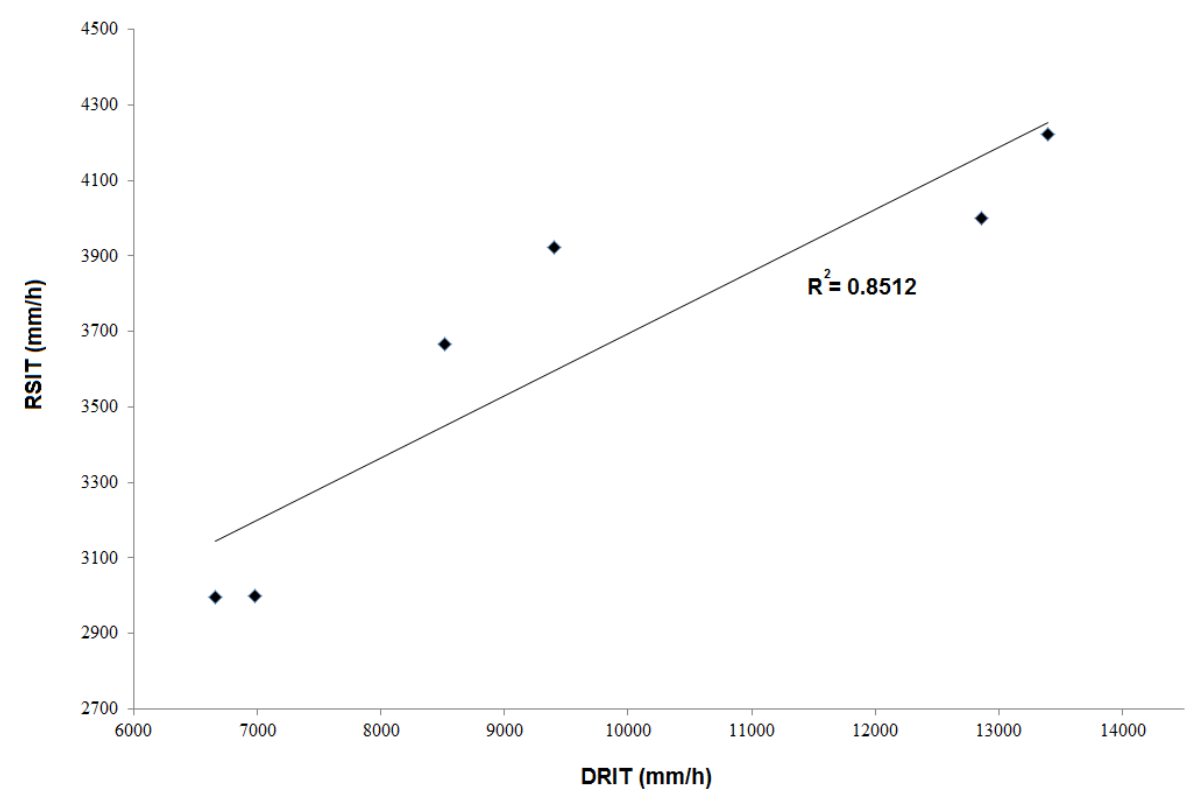

\section{Discussion}

Infiltration rates were found to be substantially lower at Sites 1-3 compared to Sites 4-6 (Figure 6). Sites constructed with a geofabric layer (1-3) showed an average 38\% reduction in infiltration rates compared with sites without a geofabric layer (4-6). This result is in line with previous study findings [30,31] that have shown pavements with geofabric layers between the bedding material and subbase aggregate to have reduced infiltration rates compared to those without geofabric.

The results suggest that different construction techniques (Table 1) did not significantly affect infiltration rates. The surface infiltration rates at sites with an impermeable layer surrounding the PICP did not appear to be affected by the inclusion of an impermeable layer. This result was expected as all sites were drained by subsurface drainage lines.

The depth of aggregate layer was also analysed to investigate whether this element of construction would impact on infiltration rates. Consistent with predictions, infiltration rates at Sites 1 and 4, constructed with shallow $(300 \mathrm{~mm})$ aggregate layers, did not vary substantially from other sites with deeper $(480 \mathrm{~mm})$ aggregate layers. This was probably because clogging is known to occur predominantly at the surface of the pavement structure and not in subbase layers [16].Garden beds located adjacent to Sites 1, 3, 4 and 6 were predicted to deliver a higher organic sediment load on to the PICP resulting in increased clogging and subsequent decreased infiltration rates during tests. Although visual inspection of these sites indicated larger amounts of visible organic matter on the surface compared to other sites, the study results did not support the conclusion that this factor impaired infiltration rates. However, due to the relatively young age of the pavement, clogging from deposition of organics may not yet be evident at these sites. Although within-site variation for both test 
methods was found to be similar, the variability in infiltration rates between test replicates between sites was found to be lower when using the RSIT. This suggests that fewer tests may be required using the RSIT method to achieve representative results on larger PICP areas or in situations where replicate tests are not feasible. The current standard methodology stipulates three tests for areas up to $2500 \mathrm{~m}^{2}$ [32]. Due to the reduction in test result variability of about $30 \%$ found in this study, we suggest a RSIT spacing frequency of three tests for areas up to $3000 \mathrm{~m}^{2}$.

Despite the disparity in infiltration measurement results regression analysis found a strong correlation between the two methods. This correlation is a statistical demonstration that the new RSIT may be accepted as a valid infiltration test method, providing similar and comparable results to an industry-wide accepted method for infiltration testing. The low variability in RSIT test results combined with the strong correlation between methods used, suggest that the DRIT method can be used to obtain realistic (rainfall based) infiltration rates. However, a factor of 0.4 needs to be applied to results obtained using the DRIT method.

The DRIT infiltration rate results clearly demonstrated the anticipated effects of the unrealistic pressure heads used in the test that force water through the pavement surface. In contrast, the RSIT test procedure does not produce unrealistic pressure heads, resulted in lower and less variable infiltration rates.

There were also practical advantages of using the RSIT including circumventing the issue of horizontal water leakage, thereby overcoming the need for a sealant. The device was not time consuming to set up, the testing was fast, efficient and easy to reproduce, and there was no post-test clean up required as there is for the standard test methodologies using sealant application. Including set-up time, the duration of each RSIT was about 5 min.

The comparatively low variability in results and larger test area used by the RSIT may also eliminate the need for multiple tests on large sites, which would significantly increase the speed of testing over larger areas or across numerous sites.

The simulated rain infiltrometer was found to be highly portable, user-friendly and able to provide a close approximation of natural rainfall conditions and intensities throughout the duration of infiltration testing.

\section{Conclusions}

Measurement of infiltration rates of PICPs has previously been problematic for a variety of reasons, including a lack of an accepted standard methodology applicable for use on permeable pavements and the practical difficulties in modifying and applying existing testing methodologies. This study examined and compared the performance of two PICP surface infiltration rate measurement methods: a modified Double-Ring Infiltrometer Test (DRIT), and a new Rainfall Simulation Infiltrometer Test (RSIT).

This study found that the new RSIT was a reliable method for estimating water infiltration rates of PICPs, providing comparable results to the DRIT. A positive correlation $\left(R^{2}=0.85\right)$ was found demonstrating parity between the two methods. The new RSIT methodology reliably measured infiltration while successfully incorporating an element of simulated rainfall, potentially rendering tests more realistic. The new RSIT test was also able to overcome some of the technical problems with existing infiltrometers and hard permeable surfaces including horizontal water leakage (use of sealant), 
unrealistic pressure heads (water level), and portability. Although the RSIT involves considerable setup costs, these may be recovered over time due to increased speed of testing when undertaking multiple tests, reducing overall operator costs.

Supplementary replicate testing of the simulated rain infiltrometer on an extended range of permeable pavements is recommended to confirm results and further validate the ability of the device to accurately measure infiltration on pavements experiencing different degrees of clogging, and ensure a reliable approximation of a range of natural rainfall characteristics in terms of drop size and velocity.

\section{Acknowledgments}

The authors would like to thank the University of the Sunshine Coast technical staff for assistance on this project. The project was jointly funded by the Sunshine Coast Council, University of the Sunshine Coast and an Australian Research Council Linkage Project Grant (LP120200678).

\section{Author Contributions}

This study was undertaken as a collaborative research project by the University of the Sunshine Coast in Australia and Frankfurt University of Applied Sciences in Germany. The experimental design of the project was undertaken by Terry Lucke and Peter Nichols. The majority of the experimental field work was conducted by Peter Nichols with assistance from Terry Lucke. The paper was written by all three authors equally.

\section{Conflicts of Interest}

The authors declare no conflict of interest.

\section{References}

1 Carol, R.J. Identification and quantification of the hydrological impacts of imperviousness in urban catchments: A review. J. Environ. Manag. 2011, 92, 1438-1448.

2 Lan, J.; Liu, B. Comparing the Purification effects of sewage water treated by different kinds of porous eco-concrete. In Proceedings of the 5th International Conference on BioInformatics and Biomedical Engineering, Wuhan, China, 10-12 May 2011.

3 Park, S.-B.; Tia, M. An experimental study on the water purification properties of porous concrete. Cem. Conc. Res. 2004, 34, 177-184.

4 Bernot, M.J.; Calkins, M.; Bernot, R.J.; Hunt, M. The influence of different urban pavements on water chemistry. Road Mater. Pavement Des. 2011, 12, doi:10.1080/14680629.2011.9690357.

5 Dietz, M.E. Low Impact Development Practices: A Review of Current 17 Research and Recommendations for Future Directions. Water Air Soil Pollut. 2007, 186, 351-363.

6 Commonwealth Scientific and Industrial Research Organistion (CSIRO). Victorian Committee: Urban Stormwater: Best-Practice Environmental Management Guidelines; CSIRO Publishing: Melbourne, Australia, 1999. 
7 Dierkes, C.; Kuhlmann, J.; Kandasamy, J.; Angelis, G. Pollution Retention Capability and Maintenance of Permeable Pavements. In Proceedings of the 7 th International Conference on Urban Drainage, Portland, OR, USA, 8-13 September 2002.

8 Legret, M.; Colandini, V.; LeMarc, C. Effects of a Porous Pavement with Reservoir Structure on the Quality of Runoff Water and Soil. Sci. Total Environ. 1996, 189-190, 335-340.

9 Legret, M.; Nicollet, M.; Colandini, V.; Raimbault, G. Simulation of Heavy Metal Pollution from Stormwater Infiltration through a Porous Pavement with Reservoir Structure. Water Sci. Technol. 1999, 39, 119-125.

10 Pratt, C.J.; Newman, A.P.; Bond, P.C. Mineral Oil Bio-Degradation within a permeable pavement: Long term observations. Water Sci. Technol. 1999, 39, 103-109.

11 Baladès, J.D.; Legret, M.; Madiec, H. Permeable pavements: Pollution management tools. Water Sci. Technol. 1995, 32, 49-56.

12 Pratt, C.J. Permeable Pavements for Stormwater Quality Enhancement. In Stormwater Quality Enhancement-Source Control, Retrofitting and Combined Source Technology; Torno, H.C., Ed.; American Society of Civil Engineering: Reston, VA, USA, 1990; pp. 131-155.

13 Brattebo, B.O.; Booth, D.B. Long term stormwater quantity and Quality Performance of Permeable Pavement Systems. Water Res. 2003, 37, 4369-4376.

14 Collins, K.A.; Hunt, W.F.; Hathaway, J.M. Hydrologic Comparison of Four Types of Permeable Pavement and Standard Asphalt in Eastern North Carolina. J. Hydrol. Eng. 2008, 13, 1146-1157.

15 Yong, C.; Deletic, A. Factors That Predict Clogging through Porous Pavements. In Proceedings of the 7th International Conference on Water Sensitive Urban Design, Melbourne, Australia, 21-23 February 2012.

16 Borgwardt, S. Long Term In-Situ Infiltration Performance of Permeable Concrete Block Pavement. In Proceedings of the 8th International Conference on Concrete Block Paving, San Francisco, CA, USA, 6-8 November 2006.

17 Pezzaniti, D.; Beecham, S.; Kandasamy, J. Influence of Clogging on the Effective Life of Permeable Pavements. J. Water Manag. 2009, 162, 76-87.

18 Bean, E.Z.; Hunt, W.F.; Bidelspach, D.A.; Smith, J.E. Evaluation of Four Permeable Pavement Sites in Eastern North Carolina for Runoff Reduction and Water Quality Impacts. J. Irrig. Drain. Eng. 2007, 133, 583-592.

19 Fassman, E.; Blackbourn, S. Urban Runoff Mitigation by a Permeable Pavement System over Impermeable Soils. J. Hydrol. Eng. 2010, 15, 475-485.

20 Lucke, T.; Beecham, S. Field Investigation of Clogging in a Permeable Pavement System. J. Build. Res. Inf. 2011, 39, 603-615.

21 Boogaard, F.; Lucke, T.; Beecham, S. Effect of Age of Permeable Pavements on Their Infiltration Function. Clean Soil Air Water 2013, 41, 146-152.

22 Li, H.; Harvey, J.; Kendall, A. Field Measurement of Albedo for Different Land Cover Materials and Effects on Thermal Performance. Build. Environ. 2013, 59, 536-546.

23 American Society for Testing and Materials (ASTM). D3385-09 Standard Test Method for Infiltration rate of Soils in Field Using Double-Ring Infiltrometer; ASTM: West Conshohocken, PA, USA, 2009. 
24 Bean, E.Z.; Hunt, W.F.; Bidelspach, D.A.; Smith, J.E. Study on the Surface Infiltration Rate of Permeable Pavements. In Proceedings of the 1st Water and Environment Specialty Conference of the Canadian Society for Civil Engineering, Saskatoon, SK, Canada, 2-5 June 2004.

25 Gerrits, C.; James, W. Restoration of Infiltration Capacity of Permeable Pavers. In Proceedings of the 9th International Conference on Urban Drainage, Portland, OR, USA, 8-13 September 2002.

26 Dierkes, C.; Lohmann, M.; Becker, M.; Raasch, U. Pollution Retention of Different Permeable Pavements with Reservoir Structure at High Hydraulic Loads. In Proceedings of the 10th International Conference on Urban Drainage, Copenhagen, Denmark, 21-26 August 2005.

27 Dougherty, M.; Hein, M.; Martina, B.; Ferguson, B. Quick Surface Infiltration Test to Assess Maintenance Needs on Small Pervious Concrete Sites. J. Irrig. Drain. Eng. 2011 137, 553-563.

28 Herngren, L. Build-Up and Wash-Off Process Kinetics of PAHs and Heavy Metals on Paved Surfaces Using Simulated Rainfall. Ph.D Thesis, Queensland University of Technology, Brisbane, Australia, 2005.

29 Meyer, L.D. Rainfall Simulators for Soil Conservation Research. In Soil Erosion Research Methods; Lal, R., Ed.; Soil and Water Conservation Society: Ankery, IA, USA, 1988.

30 Mullaney, J.; Jefferies, C.; Mackinnon, E. The Performance of Block Paving with and without a geofabric in the sub-base. In Proceedings of the 12th International Conference on Urban Drainage, Porto Alegre, Brazil, 11-15 September 2011.

31 Rowe, A.A.; Borst, M.; O’Connor, T.P. Pervious Pavement System Evaluation. In Proceedings of the World Environmental and Water Resources Congress, Great River, Kansas City, MS, USA, 17-21 May 2009.

32 American Society for Testing and Materials (ASTM). C1781-13 Standard Test Method for Surface Infiltration Rate of Permeable Unit Paving; ASTM: West Conshohocken, PA, USA, 2013.

(C) 2014 by the authors; licensee MDPI, Basel, Switzerland. This article is an open access article distributed under the terms and conditions of the Creative Commons Attribution license (http://creativecommons.org/licenses/by/3.0/). 